\title{
Potenciales Propiedades Probióticas de Lactobacillus Plantarum CRL 725 Sobreproductor de Riboflavina
}

Marianela Juárez del Valle (I), Jonathan Laiño (I), Adna Yépez (II), Rosa Aznar (III,II), Graciela Vignolo (I), Graciela Savoy de Giori (I), Jean Guy LeBlanc (I)

(I) CERELA-CONICET - Centreo de Referencia para Lactobacilos (Chacabuco 145, San Miguel de Tucuman, ARGENTINA), (II) U. Valencia - Departamento de Microbiología y Ecología, U de Valencia (Av. Dr. Moliner, 50, 46100, Burjassot, Valencia, Spain), (III) IATA-CSIC - Instituto de Agroquímica y Tecnología de Alimentos (Av. Catedrático Agustín Escardino, 7, 46980, Paterna, Valencia, España)

\section{Resumo}

Introducción: Lactobacillus (Lb.) plantarum CRL 725 es capaz de incrementar la concentración inicial de riboflavina en extracto acuoso de soja. La riboflavina (vitamina B2) es una vitamina esencial ya que se encuentra involucrada en numerosas reacciones de óxido-reducción de diferentes vías metabólicas. El ser humano es incapaz de sintetizar riboflavina por lo cual debe ser ingerida diariamente ya que en el organismo no existen depósitos de la misma. Materiales y métodos: En este estudio se evaluaron ciertas propiedades probióticas de Lb. plantarum CRL 725. La simulación al tracto gastrointestinal (TGI) fue realizada en tres pasos sucesivos: exposición a una solución de pepsina, solución de bilis y solución de pancreatina + bilis, empleando como matriz alimentaria un extracto acuoso de soja. Se estudió la actividad antimicrobiana frente a las cepas de Salmonella enterica CECT 4138T, Listeria innocua CECT 910T y Escherichia coli O157:H7 CECT 5947. Para evaluar la sensibilidad frente a antibióticos se probaron ampicilina, gentamicina, kanamicina, eritromicina, clindamicina, tetraciclina y cloranfenicol recomendados por la EFSA (European Food Safety Authority, 2012) para Lb. plantarum. Resultados: Los resultados demostraron que Lb. plantarum CRL 725 es capaz de resistir las condiciones del TGI simuladas y presenta una fuerte inhibición frente a los patógenos evaluados (con halos de inhibición superiores a los 5 mm). Además, Lb. plantarum CRL 725 es sensible a todos los antibióticos 
requeridos por EFSA para dicha especie. Conclusiones: Lb. plantarum CRL 725 es un potencial probiótico por sus propiedades beneficiosas para la salud, siendo a su vez sensible a antibióticos. Se trata de buen candidato para el desarrollo de alimentos funcionales enriquecidos en riboflavina, que puede aportar beneficios adicionales para la salud, incluyendo un potencial de producción in situ de riboflavina, una vez que los microorganismos colonizan el intestino del huésped.

Palavras-Chave: LACTIC ACID BACTERIA, PROBIOTIC, RIBOFLAVIN, SOYMILK, VITAMINS

Agência de Fomento: 